\title{
Musculoskeletal disorders: a new approach
}

\author{
Kamiel Vanwonterghem ${ }^{\mathrm{a},{ }^{*}}$ Pongjan Yoopat ${ }^{\mathrm{b}}$, Christophe Maes ${ }^{\mathrm{c}}$ \\ ${ }^{a}$ Cergo International, Breestraat, 28 b.8, B-3500 Hasselt, Belgium \\ ${ }^{\mathrm{b}}$ Rangsit Research Institute, Rangsit University, Paholyotin Road, Muang Ake, 12000 Pathumtani, Thailand \\ ${ }^{c}$ Mensana, Gentste Steenweg, 132, 8400 Sijsele, Belgium
}

\begin{abstract}
Musculoskeletal disorders are still a major problem in daily occupational life. Despite the high incidence rates and important consequences for employees, employers and society, efficient preventive strategies seem to fail in efficiency. The reason may be found in approaching the issue via the classic post-factum analysis. The preventive measures are almost not implemented because of the low predictability to be injured which affects the awareness of the problem and the low identification with the improvement proposals. MSD belong to the cumulative diseases which require and anticipating strategy based on early detection of pre-indicating symptoms.
\end{abstract}

Keywords: musculoskeletal disorders, cumulative trauma disorders, anticipative prevention

\section{Introduction: problem description}

At present the progress in preventing Musculoskeletal disorders (MSD) seems to stagnate as demonstrated by many ad hoc initiatives as The Annual Conference Fit for Work Europe (October 2011) and related publications [1]. This paper is meant to bring an innovative idea for a better understanding of the MSD-problem and why the issue is so persistent. It also formulates arguments to the actual the prevention methods and will propose ideas about a practical tackling of the problems.

Absenteeism due to injuries and diseases put a serious hypothecation on a rational development of the economic and socio-economic systems, because the importance of the direct and indirect costs affects the strategies of new investments, planning and employment strategies. Subsequently any negative phenomenon in the actual economic crisis should be avoided or prevented. Despite the multiple actions and prevention programs in Europe [2] the outcomes are disappointing as there is no substantial improvement in the MSD/CTD occurrence as it even put question marks behind ergonomics. Far from being negative about our discipline, it might be wise to take some comments into account as for example the note about OSHA Ergonomics standards [3] which mentions "Even though statistics show that MSDs occur in large numbers and are costly to business; ergonomics remains a complex and controversial issue. Some employer associations and organizations oppose mandates ergonomic guidelines, believe the seriousness of injuries is exaggerated, and question what causes these injuries" (sic). Although other organizations defend the discipline, this warning should be taken seriously, not only to defend 'ergonomics' but also the fight against MSD/CTD.

The actual analyzing MSD prevention methods are almost stocked at the classical approach used in health and safety issues and which consist of 2 ways: 1) Studying the technical working conditions and 2) studying the effects on the people touched by an MSD.

Both study-principles are per definition "postfactual" and are logic, because they reveal effectively the causes of registered cases and refer either to the working conditions (repetitive work, material handling, over-exertion,...) or to the injuries (carpal tunnel syndrome, low back pain, hernia, tension neck syndromes etc...). 
It is also logic that, following the classical considerations about prevention, the injuries should be eliminated, cq reduced, but the change of working conditions may meet resistance from management (return-on-investment) and, at present, there are no efficient individual protective systems unless collective organizational measures, but these again go back to management.

The many 'post-factual' analyzing methods are concentrated on the working conditions: checklists and statistics about incidence and prevalence but the almost uncountable developed assessment methods may reveal risks but remain rather sterile.

This can be explained by the fact that in a feedback analysis the 'effect-causes' relation is immediate - as it also may occur in some 'accidental' MSDs where the overexertion of an activity is not justified (e.g. hernia when lifting bags of $>50 \mathrm{~kg}$ ), but many damages such as a hernia, occur during a movement which is not related to any job performance (e.g. being touched by a hernia when getting up out of a cozy corner when watching TV).

In fact the MSD refers too much to categories of the observed injury or disease at the moment the damage is observed (direct causes), but not to the preindicating symptoms occurring in the period before 'the' appearing injury momentum. . Therefore the term "Cumulative Trauma Disorders" (CTD) is more appropriate than MSD because it concerns the real antecedents, which are the predicting factors of an increasing poisoning of the muscle-system by successive additions' as sign of imbalances between workload and the operators' capacity.

Managing the imbalances between load and capacity (between the external and internal factors) is the domain of ergonomics, and this offers opportunities to handle over-load, (the work-required conditions pass the individuals' capacity with a certain extend (small or important). Under-load issues - as appears when the operators' capacity is higher than the challenges in workload - are less important but may create problems on long term by losing some of the maximal capacity.

In most cases the onset of CTD risks starts when the external work related factors do not match with the internal capacity or when the operators' perception and behavioral decision making are exposed to - or determined by - inappropriate designed working conditions (task, organization and environment)..

Besides the necessity to study the imbalances, ergonomics will have to face a confrontation with challenges and conflicts. A first possible conflict may occur in the dichotomy between management and employees. Management is normally responsible for the external conditions whereas the operators are responsible for the operational Performance.

Management, steered by their golden economic principle of 'return-on-investment' is often confronted with limited resources and production costs of which the indirect costs e.g. 'social' cost (insurances, social security systems, from loss of production, absenteeism, etc.) are largely underestimated, though sometimes neglected.

Operators' responsibility depends on 'return-onproductivity': an adequate remuneration (salary and quantitative/qualitative production) and their general contribution to achieve the enterprise goals. These include also absenteeism due to work-related and seasonal diseases or injuries and other social reasons, which not always have a direct impact on their income, but has for their own integrity, affecting the company's balances.

Therefore, a prerequisite condition for good government of an organization concerns good communication, based on mutual trust and commitment of all partners involved. However, a second challenge to be solved lies in the dichotomous character of information: objective versus subjective characteristics. The objective facts, events and quantifiable issues are concrete and essential for management. However, the subjective problems remain often in the atmosphere of individually (colored) perceived items as discomfort, complaints, pains - strains and feelings, which meet difficulties of acceptance by managers. These experiences are difficult to objectify and sometimes they are erroneously questioned and estimated as unreliable or false, especially when 'responsibility' comes in the picture. However, a good social communication is a guarantee for enterprises efficiency and this will also be true for the CTD-issue, which again opens an opportunity for 'participative' ergonomics [4] 


\section{Methodological principles}

In order to enhance the ergonomics role in the CTD-issue, two essential points are essential: a) to one must have a fundamental insight in the CTD occurrence, b) ergonomics should offer an appropriate analyzing method to be able to equilibrate the man-atwork systems.

Both, strongly linked to each other, refer to previous statements about objective and subjective information and can bridge the gap between employers and employees, by offering ideas of restoring the balance between workload and capacity.

a) The fundamentals of the 'cumulative' nature of MSD

Unless a CTD evolvesas an accident (sudden occurring injury), the evolution follows the principle of the GAS (General Adaptation Syndrome) as describe by Selye, H. (1946) [5] analogously introduced in CTDs with 4 problem related phases" an adaptation phase, followed by an adapted, a cumulative and a critical phase. Vanwonterghem, K. [6] (Figure 1)

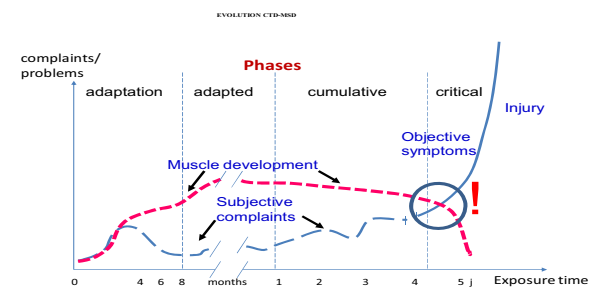

Figure 1 - Cumulative evolution in MSD-cases

During the first, the adaptation phase, the body develops the appropriate psycho-somatic qualifications to perform the job. Sometimes, annoyance may appear but will disappear quickly when continuing the job. The period lasts about 3 to 6 months, depending on the type of activities during the learning process. In the second 'adapted' phase is characterized by an equilibrium between workdemands and the operators' capacities. This period may last for the whole career, at least when recovery periods cover the effort-consequences, or when operators adjust their informal behavior to the workload. . The third phase is the cumulative phase, which starts when the psychosomatic system does not recover fully from the imbalances. The period is characterized with subjectively experienced problems evolving from moderate to heavy in time and even during work some objective capacity-failing symptoms occur. The farther in strain, the faster and the worse pain and strain evolve - the asymptotic objective criteria in the human failing are present ending suddenly in the fourth - the critical phase, the shortest one, in which there is no escape possible anymore and MSDs appear. [6]

It has been observed in field studies [6] that the MSD assessment, starting from the injury, judges over the immediate cause (the instant occurrence of disease), over general described job-activities, or over, sometimes very detailed operations of technical systems, but seldom or never over an integration of these factors on the human operator. For example: a carpal tunnel occurs in fast assembling electronic prints of which some parts need a strong pinch force of ' $x$ ' $\mathrm{kg} / \mathrm{cm}$ every $30 \mathrm{sec}$ when high visual accuracy needs the eyes to approach the part to ' $x$ ' $\mathrm{cm}$. The standing and bent posture, shoulder blockage and forearms and visual acuity may be more important for some person who have strong finger and forearm muscles.

b) Analyzing method

An efficient preventive intervention has to start before the cumulative phase becomes critical, i.e. at the level of subjective complaints i.e. paying attention when pre-announcing symptoms occur.

This can be already in the any of the 3 first phases and before the critical phase.

The link between the factors found from a return in time and the moment when the disorder appears (weeks, months, even years later) cannot serve as argument for practical adaptations in the working conditions because these conditions may have changed already before.

Furthermore, as the conditions found in that do not have a strong injury predictability, validity and reliability because so many employees escape from an MSD, (only a small amount of exposed employees become victims e.g. relative low MSD-frequency rate related to exposure time). No wonder that management is hesitating to make important 
investments or take the MSD not serious, as mentioned in introduction [3].

The only way to be successful in CTD/MSD is to ANTICIPATE, is to act on subjective warnings, i.e. employees complaints. It is logic that this resource is not always taken serious by management because of the fact the before mentioned gaps between management and operators (responsibilities, what is a profit for the one might be a disadvantage for the other, etc...e.g. productivity versus fatigue/risks) and in order to increase the credibility and reliability of the complaints, it is necessary to objectify the subjective ad hoc CTD-complaints.

In fact a stress-strain model in a participative approach [17] may solve this problem and our experiences [7] endorse the principle as it will lead to detect the basic underlying work-related causes, and enhance the communication at all hierarchic levels.

The proposed method of combining the employees' subjective experienced strain [15] with hard evident physical stressors and physiological reactions, has been developed over more than 10 years in reported research projects and in an uncountable number consulting missions in many industrial settings covering manual work [7, 8], designing mechanized and semi-automated processes [9] in administrative and control tasks $[10,11]$ or specific design oriented studies [12] as about environmental impact on employees $[13,14]$.

The subjective assessment is carried out by means of the SWI (Subjective Workload Index) $[15,16]$ which combines the individually experienced problems (LF load factors) of fatigue, observed risk, task complexity, mental concentration=, work-rhythm and problems of responsibility as well as 2 compensating factors (CF) which attenuate the views on seriousness Maximal Voluntary Contraction) which indicate part of the job creating an overload. Tackling these are more efficient than analyzing the whole departments' activities.

The strain reactions selected following the specificities of the problem e.g. cardio-vascular, thermoregulatory, and especially in case of CTD/MSD the muscular strain and the functional load. These are assessed by objectifying the muscular strain (AEMG: average electromyography of intensity of muscle contractions), loss of power in muscle capacity (MVC, maximal voluntary of the problems, namely the degree of autonomy and the interest in the job. Values are expressed on an 11point scale and SWI is calculated by SWI $\left(\sum \mathrm{LF}-\sum\right.$ CF) $/ 8$.

The SWI is used with three objectives: a) knowing and understanding the experienced problems of employees b) selecting the most urgent problems for investigation and objectification and c) formulating well -founded problem related improvement measures, including an argumentation to employers and employees. [17]. The practical indications are obtained from a detailed annex to the SWI with a full task-time analysis which is carried out to allow to make the link between the complaints and the working conditions.

The subjective SWI outcomes are firstly described/assessed (eventually objectified by existing checklists) by the work related factors in task (intensity, quantity, quality), organization (work-rest schemata, working hours, team work) and environment (climate, noise, lighting, and the biomechanical working space). In this part, some check lists are quite helpful.

The validation of the balance however is done by the element which integrates all reactions to the workload: the operator him/herself who serves as an assessment tool by reacting physiologically, psychomentally and behaviorally. Scientific and practical research have led to the establishment of a series of thresholds [6,14] for different load levels (light, medium, heavy,...) and which serve as trigger for goal-oriented improvement actions towards specific load-levels.

Rational measures are for example the introduction of an acceptable muscle load estimated as safe MSD-risk level for repetitive work (i.e. 10 to $15 \%$ of $\mathrm{MVC}$ contraction), and/or muscle fatigue (MPF mean power frequency). Depending of specific conditions also thermoregulation (body temperature, weight loss,..) and sensorial strain (auditive tts, visual fatigue, reduced reaction time, etc.) may be part of the objective measurements.

For all the possible assessment factors which are selectively taken into account, thresholds as for MVC have been developed which indicate the level of seriousness of the problem and which serve to set priorities for actions and planning on short term , medium or long term. 
More precisely for MSD the effects of workload which is affected by task (intensity and all related factors as equipment, weights, sizes,...), organization (including time weighing, work-rest schemata, product-flow schemes, etc...) and environment (physical as biomechanical) on the operator are individually assessed (physiological, behavioral, mental,....), the method includes besides the SWI, also heart rate, converted in cardiovascular load (CVL for characterizing the general fatigue Local fatigue is assessed by measuring the muscular strain (AEMG: average electromyography of intensity of muscle contractions), loss of power in muscle capacity (MVC, maximal voluntary contraction), and/or muscle fatigue (MPF mean power frequency). Depending on specific conditions also thermoregulation (body temperature, weight loss,..) and sensorial strain (audition tts, visual fatigue, reduced reaction time, etc.), handgrip force, reaction time etc... may be part of the objective measurements.

\section{Evaluation and conclusions}

As the method has been used over more than 20 years now, it has to be stated that the approach contributed effectively in improving the social climate in enterprises, especially when the complaints are confirmed with an objective assessment. These arguments are bridging the gap between management and employees and many useful hints and proposals have been developed in the mean time.

A quite successful example might be a short survey about the outcomes of a 2 years EU-CRAFT project which ran from 2002 and 2003 in a factory producing school furniture. The work included lots of machinery (sawing, polishing, formatting, and material handling: loading and unloading machines, piling materials and assembling activities which create risks for CTD. Personnel and productivity remain stable during the last 5 years. The interventions - CVL, AEMG and SWI based concerned the use of height adjusting pallet transporters which are weight steered, the remanagement of the product flow throughout workplace, the improved floor conditions for roller transporters, etc.. The discussions of the results with both management and operators, lead to a sustaining improvement about the frequency and seriousness caused by MSD. In addition, also the other risks (e.g. accidents) followed the positive trend in absenteeism, as demonstrated in Table 1.
Table 1 - 'N' cases and Los days due to MSD and other reasons in a wood-processing furniture factory

\begin{tabular}{|c|c|c|c|c|c|c|c|c|}
\hline & & 2001 & 2002 & 2003 & 2004 & $* 2005$ & 2006 & 2007 \\
\hline msd & N & 36 & 27 & 14 & 2 & 4 & 6 & 2 \\
\hline other & cases & 75 & 51 & 28 & 9 & 11 & 8 & 9 \\
\hline msd & days & 357 & 237 & 158 & 30 & 25 & 41 & 33 \\
\hline other & lost & 279 & 231 & 101 & 84 & 65 & 55 & 43 \\
\hline \multicolumn{6}{|c|}{ Crash on the way to the factory }
\end{tabular}

The table shows a good result during the 2 years of the project but more important are the years after the project was finished, which revealed a sustaining and stable positive result due to an open communication on risks and possibilities to improve the conditions. The last years the enterprise went silent and there was no follow up. From many other consulting experiences in SMEs where the same method was explained and used in a relatively short time, were successful as well, but their results were estimated as confidential and therefore not available for publication.

In conclusion: participative ergonomics supported by a methodology which combines subjective and objective information has been proven to be very efficient. However, this needs an interdisciplinary approach in which the operator is the key-element in risk assessment. The obtained information is more socio-cultural 'enterprise' linked and perceived as an added value in fighting the actual problems of the industry: keeping experienced workers employed, keep absenteeism low, increase the efficiency of production, and non the least reduce MSD cases through an anticipating and participative ergonomics method..

In order to enhance the usefulness of 'ergonomics' practical (and by preference easy to perform assessment methods) should promote the participation of exposed employees because they integrate psychosomatically all load aspects of the production processes, and are much more acceptable, because they define the problem, give arguments how and why to improve the conditions in time before the actions come too late.

Objectified complaints and subjective experiences of the exposed personnel allow an anticipating strategy which is essential and urgently needed in the fight against CTD/MSD. The practical method as described lead to results, but the complexity of the individuals at all levels in an enterprise, each in their own job which is a balance 
between the complex workload and the inter- and intra individual differences needs more scientific analysis as well in development of measurement and evaluation(thresholds) techniques. This possibly would be the answer to the statement on page 1 about Ergonomics as mentioned [3]

\section{References}

[1] Bevan, S., Quadrillo, T., McGee, R. Mahdon, M. Vavrovsky, A. and Barham, L. (2009) -Musculoskeletal Disorders in the Workplace, The Work Foundation, London

[2] Rimmer P., Podniece Z. (2007): Lighten the Load A European Campaign on Musculoskeletal Disorders. European Agency Prevention Today, Vol.3, $\mathrm{nr} 2$

[3] Wagner-March F, Hillstrom L. - OSHA Ergonomic Standards. /Em-Exp/Ergonomics.html

[4] Wilson, J. R. \& Haines, H. M. (1997). Participatory ergonomics. In G.Salvendy (Ed.), Handbook of Human Factors and Ergonomics (pp. 490-513). United States of America: John Wiley and Sons

[5] Selye H. (1946) The general adaptation syndrome and the diseases of adaptation. Journal of Clinical Endocrinology 6:pp.117-231

[6] Vanwonterghem, K. (2009). Biomechanical damage risks in SMEs - Project methodology and Introduction: considerations about results and project teamwork. in Strambi, F., Montoliu M.A. Vanwonterghem, K. Risk Assessment of Biomechanical Damage Risks in Small and Mediumsized Enterprises. Moretti \& Vitali pp55-63, pp156-165

[7] Yoopat, P., Toicharoen, T., Glinsukon, T., Vanwonterghem, K. and Louhevaara, V. (2002)- Ergonomics in Practice: physical workload in Heat Stress in Thailand. Int. J. Occup. Daf. Ergon. $8(1)$

[8] Intaranont, K. - and Vanwonterghem, K (1993) Study of the Exposure Limits in Constraining Climatic Conditions for Strenuous Tasks: an Ergonomic Approach.; Final Report Joint Research Project CI1-0519-M for The Commission of the European Communities .
[9] Verboven, J., Vanwonterghem, K., Verhaegen, P. (1992) Ergonomic Aspects of the Development of a Tunneling Machine for Coal Mining; Enhancing Industrial Performance, Taylor \& Francis, pp 91-102.

[10] Vanwonterghem, K., Rabit, M. (1988); - Brain Activity and Mental Workload in ATC-Tasks, CEE ASO2b, Report 228, Brétigny s/Orge,

[11] Vanwonterghem, K, Verboven, J. (1988) Brain Activity in Simulated Air Traffic Control Tasks, EEC Report 219, Brétigny s/Orge, France,

[12] Op De Beeck, R., Vanwonterghem, K. (1990);- Ergonomic Design Coal-cutter Station, Finalreport ECCS Project 724913-042.

[13] Kamarrudin, A.G and Vanwonterghem, K. (1995)- An Ergonomic Study of Strenuous Repetitive Tasks under Tropical Climatized and Non-Climatized Working Conditions.; Final Report Joint Research Project CI1-CT920015 for the Commission of the European Union, Feb.

[14] Manuaba, A and Vanwonterghem, K. (1996) Improvement of quality of life. Determination of exposure limits for physical strenuous jobs under tropical conditions. Final report CT90019

[15] Vanwonterghem, K., Verboven, J. and Cloostermans, M.(1985) Beoordelingslijst Subjectieve Evaluatie Arbeidsbelasting. (Subjective workload index questionnaire) -, Tijdschrift Ergonomie, Nederlandse Vereniging Ergonomie, nr. 10,3, pp. 10-14, (in Dutch)

[16] Vanwonterghem, K. (1985).A postural load evaluation technique: based on energy expenditure, heart rate and subjective appreciation. In N. Corlett, J. Wilson, and I. Manenica (eds)(1986). The Proceedings of the First Intemational Occupational Ergonomics Symposium - Zadar (Croatia). Taylor and Francis. pp. 256-269

[17] Vanwonterghem, K. - (2009) Ergonomics and Human Factors: Methodological considerations about evidence-based design of work systems. In Schlick C.M. (ed) Industrial Engineering and Ergonomics: visions, concepts, methods and tools. Springer Verlag, pp. 413-425 